\title{
Pengaruh Daya Ledak Otot Tungkai Terhadap Kemampuan Jump Shoot Atlet Klub Bolabasket
}

\author{
Fahd Mukhtarsyaf ${ }^{1}$, Irfan Arifianto ${ }^{2}$, Fahmil Haris ${ }^{3}$ \\ ${ }^{1,3}$ Program Studi Kesehatan dan Rekreasi, Fakultas Ilmu Keolahragaan, Universitas Negeri Padang. \\ ${ }^{2}$ Program Studi Pendidikan Kepelatihan Olahraga, Fakultas Ilmu Keolahragaan, \\ Universitas Negeri Padang
}

Email: fahdm6231@fik.unp.ac.id ,

\begin{abstract}
Abstrak
Penelitian ini bertujuan untuk mengetahui dan mengungkapkan pengaruh Daya Ledak Otot Tungkai terhadap kemampuan jumpshot pada atlet bola basketkota Padang. Populasi penelitian ini adalah atlet bolabasket kota Padang. Pengambilan sampel dilakukan dengan teknik purposive random sampling, sehingga jumlah sampel penelitian ini berjumlah 40 orang atlet. Teknik pengumpulan data dilakukan dengan menggunakan tes vertical jump untuk mengukur daya ledak otot tungkai, dan speed spot shooting test untuk mengukur kemampuan jump shot. Pengujian hipotesis penelitian menggunakan teknik analisis jalur. Dari hasil penelitian, dapat ditarik kesimpulan daya ledak otot tungkai secara langsung berpengaruh terhadap kemampuan jump shoot Atlet Bola Basket Kota Padang, besarnya pengaruh daya ledak otot tungkai terhadap kemampuan jump shoot melalui kekuatan otot lengan pada Atlet Bola Basket Kota Padang adalah 0,145 atau sebesar 14,5\%.
\end{abstract}

Kata Kunci: Daya ledak otot tungkai, Jump shoot

\section{Effect Of Explosive Muscle Explosion On Jump Shoot Ability At Bolabasket Club}

\begin{abstract}
This study aims to determine and reveal the effect of Leg Muscle Explosion Power on the ability to jumpshot on the basketball athletes in Padang. The population of this research is the basketball athletes in the city of Padang. Sampling was done by purposive random sampling technique, so that the number of samples of this study amounted to 40 athletes. Data collection techniques were carried out using a vertical jump test to measure the leg muscle explosive power, and a speed spot shooting test to measure the ability of a jump shot. Testing the research hypothesis using path analysis techniques. From the results of the study, it can be concluded that the leg muscle explosive power directly influences the jump shoot ability of the Padang City Basketball Athlete, the magnitude of the influence of the leg muscle explosive power on the ability to jump shoot through the arm muscle strength in the Padang City Basketball Athlete is 0.145 or equal to $14,5 \%$.
\end{abstract}

Keywords: Leg muscle explosive power, Jump shoot

\section{PENDAHULUAN}

Perkembangan ilmu pengetahuan dan

tekhnologi pada saat sekarang ini telah membawa kemajuan dalam segala bidang. Salah satunya pada bidang olahraga, khususnya olahraga bolabasket. Permainan bolabasket merupakan salah satu dari olahraga permainan yang banyak digemari oleh 179|h t t p : / / m e n s s a n a.p pj.un p.ac.id berbagai lapisan masyarakat, karna permainan bolabasket dapat dilakukan oleh anak-anak, pararemaja, dan juga orang dewasa.

Dalam permainan bolabasket,seorang
pemain dituntut selalu bergerak sambil
memperagakan teknik-teknik dasar bolabasket,



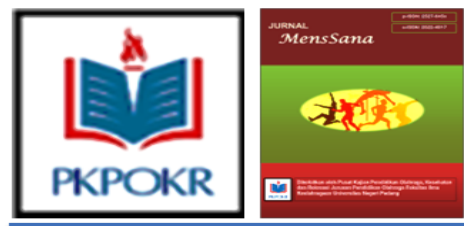

Vol. 4, No. 2; Tahun 2019

ISSN : 2527-645X, E-ISSN: 2622-4917

Penerbit:

Pusat Kajian Pendidikan Olahraga, Kesehatan dan Rekreasi,

Jurusan Pendidikan Olaharga, Fakultas Ilmu Keolahragaan, Universitas Negeri Padang

berusaha memasukkan bola kering lawan sebanyakbanyaknya tanpa mendapat gangguan dari lawan serta berusaha mencegah lawan untuk berusaha memasukan bola ke dalam ring. Hal ini artinya, untuk dapat bermain bolabasket dengan baik dibutuhkan penguasaan teknik yang baik dan kualitas fisik yang memadai karena meningkatkan keahlian bolabasket hanya akan berhasil jika pemain melatih fisiknya teratur dan berulang kali.

Menembak merupakan suatu teknik dasar yang harus dikuasai setiap pemain bola basket tanpa terkecuali. Jenis-jenis tembakan bola basket menurut buku yang diterbitkan oleh FIBA (1998) yang berjudul "Basket Ball ForEveryone" terdiri dari beberapa jenis, antara lain: The set shoot, the lay up shoot,underline shoot, the jump shoot, hook shoot, dunking, the reverse lay up. Tembakan lompat (jump shoot) adalah suatu teknik dasar menembak yang sering digunakan oleh setiap pemain untuk meraih poin dalam setiap pertandingan, tembakan lompat dapat dilakukan oleh setiap pemain pada posisi manapun, biasanya dalam suatu tim bola basket kemampuan tembakan lompat hanya dimiliki oleh seorang pemain yang berkarakter sebagai seorang pemain menembak (shooter) tetapi pada kenyataannya sekarang kemampuan tembakan lompat dapat dilakukan oleh setiap pemain dalam suatu tim, karena kemenangan suatu pertandingan ditentukan oleh jumlah poin yang dihasilkan melalui tembakan yang dibuat suatu tim.

Secara teknis gerakan tembakan lompat adalah gerakan yang mudah dilakukan, karena tembakan terdiri dari beberapa tahap/fase $\mathbf{1 8 0 | h t t p : / / m e n s s a n a \cdot p p j . u n p . a c . i d ~}$ gerakan, antara lain dari gerakan lompatan, gerakan tangan dalam menembak, fokus mata terhadap sasaran/target, release bola dan gerakan lanjutan.

Atlet bolabasket kota Padang dalam melakukan tembakan khususnya tembakan lompat sering kurang maksimal sehingga banyak peluang untuk menciptakan pointer buang dengan percuma dan juga sering terjadi kesulitan dalam melakukan gerakan tembakan lompat. Seringnya pemain gagal dalam melakukan tembakan lompat hendaknya perlu dicari dan ditelusuri faktor-faktor penyebabnya.

Sesuai dengan ide permainan bolabasket itu sendiri, memasukkan bola ke dalam ring lawan merupakan tujuan utama untuk memperoleh kemenangan dan oleh sebab itu, menembakkan bola ke dalam ring harus benar-benar terarah dengan teknik menembak yang harus dikuasai dengan baik dan benar. Terkait dengan ide permainan bolabasket, Sodikoen menyatakan bahwa dalam bermain sudah seharusnya para pemain dapat "memasukkan bola sebanyak-banyaknya ke ring lawan dan mempertahankan ring kita dari serangan lawan". Berdasarkan pendapat tersebut, maka untuk dapat meraih prestasi dalam permainan bolabasket tentunya para pemain harus berusaha memasukkan bola ke ring lawan sebanyak mungkin, oleh sebab itu perlu adanya teknik menembak.

Menembak merupakan sasaran akhir dalam permainan bolabasket. Keberhasilan suatu regu dalam permainan selalu ditentukan oleh keberhasilan memasukkan bola ke dalam keranjang lawan sebanyak- banyaknya dibandingkan lawannya tersebut. Krause (1999:67) menyatakan dalam 

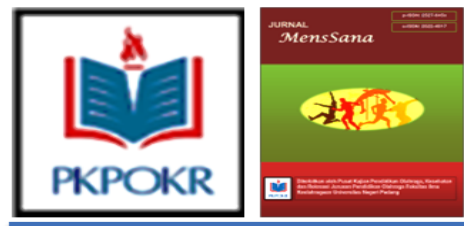

Vol. 4, No. 2; Tahun 2019

ISSN : 2527-645X, E-ISSN: 2622-4917

Penerbit:

Pusat Kajian Pendidikan Olahraga, Kesehatan dan Rekreasi,

Jurusan Pendidikan Olaharga, Fakultas Ilmu Keolahragaan, Universitas Negeri Padang

belajar menembak harus menggunakan prinsip

jumpshot

dalam

situs

BEEF yaitu:

B-Balance, saat menangkap bola tekuklah lutut dan mata kaki dan mengatur tubuh dalam keadaan seimbang.

E-Eyes, agar tembakan menjadi akurat pemain harus fokus pada target.

E-Elbow, pertahankan posisisiku agar pergerakan lengan tetap vertikal.

F-Followthrough, kunci siku dan lepaskan gerakan lengan serta jari-jari mengikuti ke arah ring.

Menembak merupakan salah satu teknik dasar bermain bolabasket yang harus diakui oleh setiap pemain. Menembak merupakan unsur penting dalam suatu pertandingan karena kemenangan ditentukan oleh banyaknya bola yang masuk dalam ring. Sodikoen (1992:70) berpendapat : "Setiap serangan selalu berusaha dapat berakhir dengan tembakan. Oleh karena itu unsur menembak ini merupakan teknik dasar yang harus dipelajari dengan baik dan benar serta ditingkatkan kemampuannya". Berdasarkan penjelasan sebelumnya, bagaimana shooting menjadi satu teknik yang sangat penting dalam permainan bolabasket. Salah satu dari sekian banyak teknik menembak bola ke ring diantaranya adalah jumpshot, apakah itu dari posisi yang diam atau saat bergerak. Jumpshot berasal dari kata "jump"dan "shoot", jump artinya meloncat dan shoot artinya menembak. Jadi jump shot adalah tembakan sambil meloncat. Menurut kamus istilah olahraga jump shot adalah tembakan yang dilakukan oleh pemain sambil meloncat (Depdikbud,1982:81). Menurut Imam Suyadi (1979:87) tentang pengertian http://sanggili.blogspot.com/2010/01/skripsi-

olahraga-1-bab-1-dan-2.html yaitu: Jump shot adalah suatu tembakan yang dilakukan dengan jarak,baik dilakukan dengan jarak dekat maupun jarak jauh dengan posisi keranjang (ring), sehingga seolah-olah keranjang (ring) tingginya sangat sejajar dengan kita. Jump shot merupakan tembakan sambil melompat yang sangat membutuhkan kemampuan lompatan yang bagus.

Jump shot merupakan salah satu teknik menembak yang paling sering digunakan dalam bolabasket modern dewasa ini, apakah itu dilakukan dalam suatu pergerakan atau dari posisi ditempat. Maka dari itu harus diberikan kepada atlet sedini mungkin,agar penguasaan jump shot lebih baik dan mahir. Ini sepertiyang dikemukakan oleh Wooden bahwa latihan menembak harus menitik beratkan, membentuk dan meningkatkan jumpshot (1979:97).

Pada atlet pemula bolabasket, teknik jump shot merupakan teknik yang sulit untuk dipelajari gerakannya dan jarang dilakukan. Teknik tersebut memerlukan koordinasi gerak kaki dan tangan yang baik dan membutuhkan latihan yang disiplin. Teknik jump shot sangatlah diutamakan harus dikuasai bagi para pemain bolabasket itu sendiri. Pada permainan bolabasket apabila seorang pemain menguasai teknik jump shot dengan baik pada posisi disegala tempat, maka dalam pertandingan pemain tersebut merupakan ancaman bagi lawan dalam mencetak angka pada setiap saat.

Daya Ledak Otot Tungkai 

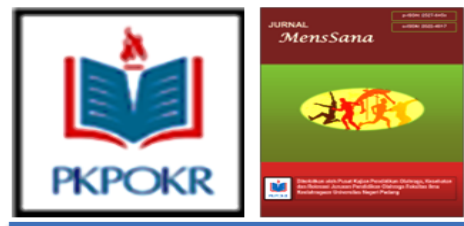

Vol. 4, No. 2; Tahun 2019

ISSN : 2527-645X, E-ISSN: 2622-4917

Penerbit:

Pusat Kajian Pendidikan Olahraga, Kesehatan dan Rekreasi,

Jurusan Pendidikan Olaharga, Fakultas Ilmu Keolahragaan, Universitas Negeri Padang

Dalam setiap aktivitas olahraga, otot merupakan komponen tubuh yang dominan dan tidak dapat dipisahkan. Semua gerakan yang dilakukan oleh manusia karena adanya otot, tulang, persendian, ligamen,serta tendon sehingga gerakan dapat terjadi melalui gerakan tarikan otot serta jumlah serabut otot yang diaktifkan. Daya ledak merupakan salah satu elemen kondisi fisik yang banyak dibutuhkan dalam olahraga.

Bompa(2009:263) menyatakan it appears that both force and velocity are important in human movement, because the product of the set wovariables is power. Dapatdikatakan bahwa daya ledak merupakan kemampuan yang sangat penting dalam setiap pergerakan dalam bolabasket karena daya ledak adalah gabungan dari dua variabel yaitu kekuatan dan kecepatan.

Davebellomo (2010:7) berpendapat bahwa power differs from strength because it includes the elementof time. Daya ledak tidak sama dengan kekuatan. Untuk mendapatkan daya ledak yang bagus, kita harus menambahkan kecepatan di dalam kekuatan tersebut agar otot-otot terlatih untuk bekerjasama seefisien mungkin. Hal senada juga di kemukakan Phillips dan Hornak (1979:225) bahwa daya ledak otot tungkai dapat didefenisikan sebagai kemampuan untuk mengeluarkan tenaga maksimum dalam waktu yang sesingkat mungkin. Daya ledak adalah gabungan dari komponen kekuatan dan kecepatan. Para ahli dalam bidang olahraga memberikan defines tentang daya ledak yang berbeda-beda, akan tetapi pada umumnya memberikan pengertian yang sama, seperti yang dikemukakan oleh Sajoto (1995:67), bahwa power atau daya ledak adalah kemampuan seseorang untuk melakukan kekuatan maksimal dengan usahausaha yang dikerahkan dalam waktu yang sependekpendeknya. Harsono (1988:199) mendefinisikan power sebagai hasil dari forcex velocity, dimana force sepadan dengan strength dan velocity dengan speed. Dapat dikatakan daya ledak adalah kemampuan otot atlet untuk mengatasi tahanan beban dengan kekuatan dan kecepatan maksimal dalam satu gerak yang utuh.

Dari definisi di atas, dapat diketahui bahwa dua unsure pokok yang menentukan daya ledak adalah kekuatan (strength) dan kecepatan (speed). Daya ledak merupakan komponen gerak sangat penting untuk melakukan suatu aktivitas yang sangat berat yang dilakukan dalam waktu yang sesingkat mungkin. Wilkens (1998:200) menyatakan Power can be measured by calculatinga formula: force time distance divided by time. Dengan kata lain daya ledak dapat diukur dengan cara jarak tempuh kekuatan dibagi oleh waktu. Bolabasket terdiri dari $20 \%$ aerobik dan $80 \%$ anaerobik dengan banyak faktor yang memepengaruhi pemakaian rasio energy bagi setiap pemain. Sejumlah pemain bergerak untuk mendapatkan ruang gerak, posisi dan berlari dengan percepatan-percepatan tertentu. Dengan energy total yang dibutuhkan untuk pertandingan kira-kira selama 2 jam, maka kontribusi system energy berubah secara berkesinambungan. Bolabasket dikenal sebagai permainan yang membutuhkan kebugaran anaerobik yang tinggi, oleh karena itu suatu pertandingan selama 2 jam dibagi menjadi 4 segmen. Berdasarkan pendapat di atas dapat 

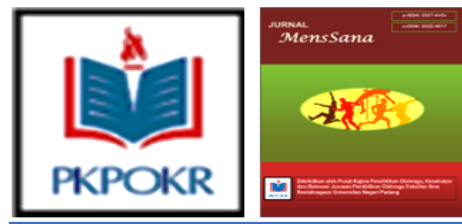

Vol. 4, No. 2; Tahun 2019

ISSN : 2527-645X, E-ISSN: 2622-4917

Penerbit:

Pusat Kajian Pendidikan Olahraga, Kesehatan dan Rekreasi,

Jurusan Pendidikan Olaharga, Fakultas Ilmu Keolahragaan, Universitas Negeri Padang

dikatakan bahwa sebagian besar dari seluruh gerakan dalam permainan bolabasket dimotori oleh kemampuan daya ledak, namun tidak tertutup didukung oleh kemampuan fisiklainnya seperti daya tahan dan kekuatan. Ada 8 gerak dasar yang perlu dikuasai dilandasi dari kemampuan dayaledak, seperti (1) mengubah kecepatan langkah, (2) mengubaharah, (3) satu-dua stop, (4) melompatstop, (5) berputar maju, (6) berputar ke belakang, (7) melompat dengan dua kaki dan (8) melompat dengan satu kaki.Efektifitas perubahan langkah berawal dari kemampuan daya ledak yang baik. Daya ledak otot tungkai sangat membantu dalam melakukan gerakan melompat. Dengan memiliki daya ledak otot tungkai yang besar, maka kemampuan melompat ke atas (vertical jump) pun lebih tinggi dan sangat membantu dalam melakukan jump shoot.

\section{METODE}

Jenis penelitian ini menggunakan teknik analisis jalur, bertujuan untuk melihat seberapa besar pengaruh hubungan antara daya ledak otot tungkai terhadap kemampuan Jump shoot atlet bolabasket kota Padang, baik secara langsung maupun tidak langsung. Populasi dalam penelitian ini adalah seluruh atlet bolabasket kota Padang yang berjenis kelamin laki-laki. Teknik pengambilan sampel menggunakan teknik purposive random sampling, sehingga jumlah sampel yang digunakan dalam penelitian ini adalah 40 orang atlet.

Daya ledak otot tungkai merupakan gabungan antara kekuatan dan kecepatan. Dimana gerakannyang membutuhkan kekuatan yang maksimal dalam waktu yang sesingkatsingkatnya. Kemampuan daya ledak otot tungkai dapat diukur dengan tes vertical jump dengan mendapat nilai selisih raihan dan jangkauan. Kemampuan jump shot merupakan salah satu jenis kemampuan menembak yang diawali dengan sebuah lompatan vertical sebelum melepaskan bola.Kemampuan jump shot dapat diukur dengan menggunakan Speed Spot Shooting Tes

\section{Hasil dan Pembahasan}

\section{Hasil Penelitian}

Berdasarkan dari hasil pengambilan data kemampuan daya ledak otot tungkai, dan kemampuan jump shoot atlet bola basket Kota Padang sebanyak 40 atlet. Maka didapat hasil dari pengolahan data tersebut, sebagai berikut:

Uji Normalitass

Tests of Normality

\begin{tabular}{|l|l|l|l|l|l|l|}
\hline \multirow{2}{*}{} & \multicolumn{3}{|l|}{ Kolmogorov-Smirnov $^{\mathrm{a}}$} & \multicolumn{3}{|l|}{ Shapiro-Wilk } \\
\cline { 2 - 7 } & Statistic & df & Sig. & Statistic & df & Sig. \\
\hline $\begin{array}{l}\text { Daya Ledak } \\
\text { Otot Tungkai }\end{array}$ & 0,143 & 21 & $0,200^{*}$ & 0,948 & 21 & 0,313 \\
\hline
\end{tabular}

*. This is a lower bound of the true significance.

Berdasarkan tabel test of normality di atas, dapat dilihat bahwa nilai Signifikasi senesar 0.313 yang mana nilai ini lebih besar dari 0.05 sehingga dapat disimpulkan data berdistribusi normal.

Tests of Normality

\begin{tabular}{|c|c|c|c|c|c|c|}
\hline & \multicolumn{3}{|c|}{ Kolmogorov-Smirnov ${ }^{\mathrm{a}}$} & \multicolumn{3}{|c|}{ Shapiro-Wilk } \\
\hline & Statistic & df & Sig. & Statistic & df & Sig. \\
\hline $\begin{array}{l}\text { Kemampuan } \\
\text { Jump Shoot }\end{array}$ & 0,188 & 21 & 0,051 & 0,930 & 21 & 0,140 \\
\hline
\end{tabular}

a. Lilliefors Significance Correction 

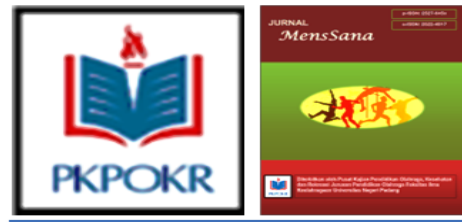

Vol. 4, No. 2; Tahun 2019

ISSN : 2527-645X, E-ISSN: 2622-4917

Penerbit:

Pusat Kajian Pendidikan Olahraga, Kesehatan dan Rekreasi,

Jurusan Pendidikan Olaharga, Fakultas Ilmu Keolahragaan, Universitas Negeri Padang
Berdasarkan tabel test of normality di atas, dapat dilihat bahwa nilai Signifikasi senesar 0.140 yang mana nilai ini lebih besar dari 0.05 sehingga dapat disimpulkan data berdistribusi normal.

\section{Pembahasan}

\section{Pengaruh Daya Ledak Otot Tungkai Secara Langsung terhadap Kemampuan Jump}

\section{ShootAtlet Bola Basket Kota Padang}

Berdasarkan hasil uji individual yang dilakukan $\mathrm{X}_{1}$ terhadap Y didapatkan bahwa hasil koefesien jalur $\rho_{\mathrm{YX} 1}=0.698$. Berdasarkan hasil perhitungan yang dilakukan dengan menggunakan proram SPSS 23 diperoleh nilai sig $=0.010$ lebih kecil dari nilai $\alpha=$ 0.05 , nilai $0.010<0.05$ maka dalam hal ini $\mathrm{H}_{\mathrm{a}}$ diterima dan $\mathrm{H}_{0}$ ditolak yang berarti koefesien anlisis jalur signifikan. Jadi, daya ledak otot tungkai secara langsung berpengaruh terhadap kemampuan jump shootAtlet Bola Basket Kota Padang. Besarnya pengaruh daya ledak otot tungkai terhadap kemampuan jump shootAtlet Bola Basket Kota Padang adalah sebagai berikut:

$=\rho_{\mathrm{yx} 1}{ }^{2} \times 100 \%$

$=0,698^{2} \times 100 \%$

$=48,7 \%$

Pengaruh Daya Ledak Otot Tungkai Secara

Tidak Langsung terhadap Kemampuan Jump Shoot Melalui Kekuatan Otot LenganAtlet Bola

\section{Basket Kota Padang}

Berdasarkan hasil uji analisis terhadap variabel daya daya ledak otot tungkai terhadap kemampuan jump shoot melalui kekuatan otot lengan pada Atlet Bola Basket Kota Padang, didapatkan hasil sebagai berikut:
Pengaruh langsung $\mathrm{X}_{1}$ terhadap $\mathrm{Y} \quad\left(\rho_{\mathrm{yx} 1}\right) \quad 0.698$

Pengaruh $X_{1}$ terhadap $X_{3} \quad\left(\rho_{x 31}\right) \quad-0.559$

Pengaruh langsung $\mathrm{X}_{3}$ terhadap $\mathrm{Y} \quad\left(\rho_{\mathrm{yx} 3}\right) \quad 0.566$

$\begin{array}{ll}\text { Pengaruh tidak langsung }=\quad & \rho_{\mathrm{YX} 1}+\left(\rho_{\mathrm{x} 31} \times \rho_{\mathrm{Yx} 3}\right) \\ & 0.698+(-0.559) \times 0.566 \\ & 0.698+(-0.316) \\ & 0.381 \\ & \\ \text { Sumbangan } \rho_{\mathrm{xm} \mathrm{x} 1}=\quad & 0.381^{2} \times 100 \% \\ & 0.145 \times 100 \% \\ & 14,5 \%\end{array}$

\section{KESIMPULAN}

Jadi berdasarkan hal di atas maka dapat ditarik kesimpulan bahwa daya ledak otot tungkai secara langsung berpengaruh terhadap kemampuan jump shoot Atlet Bola Basket Kota Padang adalah sebesar 48,7\%. Sedangkan sisanya 51,27\% dipengaruhi oleh faktor lain. Disamping itu, dapat dikatakan besarnya pengaruh daya daya ledak otot tungkai terhadap kemampuan jump shoot melalui kekuatan otot lengan pada Atlet Bola Basket Kota Padang adalah 0,145 atau sebesar $14,5 \%$.

\section{DAFTARPUSTAKA}

A.HamidsyahNoer.1993.IlmuPelatihanDasar.Surak arta:FKIPUNS.

Baumgatner, Measurement For Evaluation, (Iowa: Brown Publishers, 1982)

Bompa, O. Tudor. 1994. Theory and Methodology of Training. Dubuque, Iowa: Hunt Publishing Company.

Dave Bellomo, Kettlebell Training For Athletes, (USA: McGraw-Hill Company, 2010) 


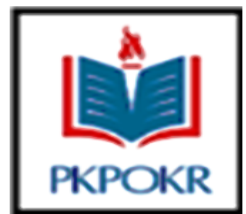

Vol. 4, No. 2; Tahun 2019

ISSN : 2527-645X, E-ISSN: 2622-4917

Penerbit:

Pusat Kajian Pendidikan Olahraga, Kesehatan dan Rekreasi,

Jurusan Pendidikan Olaharga, Fakultas Ilmu Keolahragaan, Universitas Negeri Padang

Fardi, Adnan. 1999. Bolabasket Dasar. Fakultas

Ilmu Keolahragaan: Universitas Negeri

Padang.

Gray Cook ,Athletic Body In Balance, (USA :

Human Kinetics, 2003)

Imam Sodikoen. 1992. Olahraga Pilihan Bola

Basket. Jakarta: Depdikbud Dirjen Dikti

PPTK.

Kosasih, Danny. 2008. Fundamental Basketball:

First Step to Win. Semarang: Karangturi

Media.

Krause, JerryV. 1999. Basketball Skillsand Drills.

USA: Human Kinetics.

M. Sajoto, Pembinaan Kondisi Fisik Olahraga,

(Jakarta: Depdikbud Dirjen Dikti PPLPTK,

1995)

Sarumpaet,A. 1992. Permainan Bola Besar.

SuharnoHP. 1986. Kepelatihan Olahraga.

Yogyakarta: IKIP Yogyakarta.

Undang-Undang Sistem Keolahragaan Nasional No

3 (2005:16). Pembinaan dan

Pengembangan Olahraga Prestasi Pasal

27 Ayat: 4. PT. Sinar Grafika. Wilkens,

Lenny, NBA Power Conditioning, (USA:

Human Kinetics, 1998) 